\title{
PRINCÍPIOS DA USABILIDADE E DA ACESSIBILIDADE A SEREM APLICADOS NA TV PARA FACILITAR O ACESSO AOS DEFICIENTES VISUAIS
}

\section{USABILITY AND ACCESSIBILITY PRINCIPLES TO BE APPLIED ON TELEVISION TO FACILITATE THE ACESS FOR VISUALY IMPAIRED}

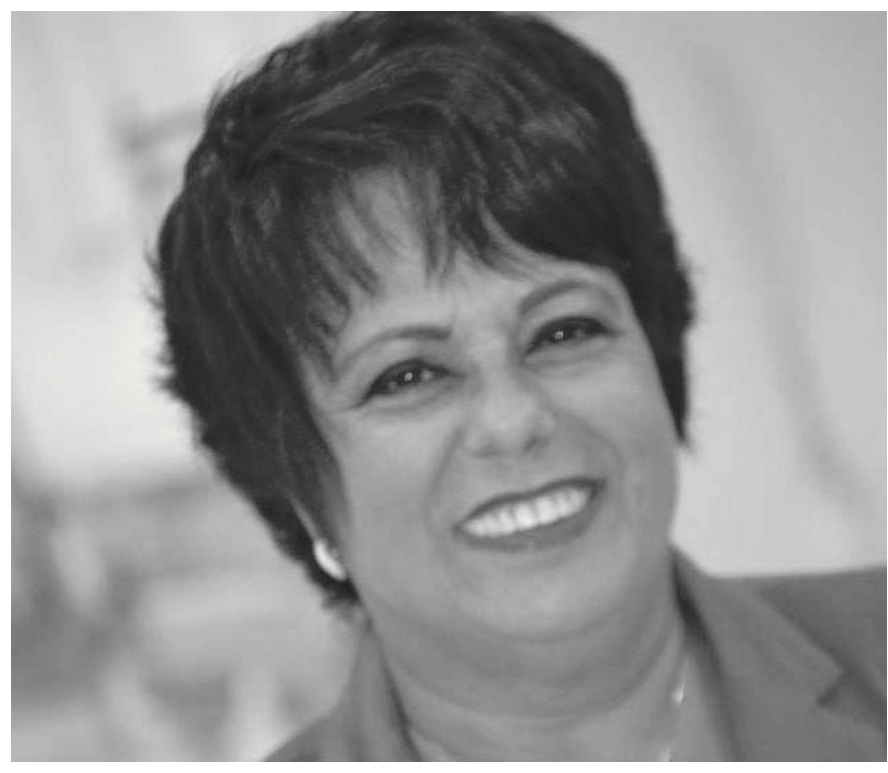

\section{Icléia Silveira}

Doutora em Design pela Pontifícia

Universidade Católica do Rio de janeiro.

Professora do Departamento de Moda/

Universidade do Estadual de Santa Catarina.

Icleiasilveira@gmail.com

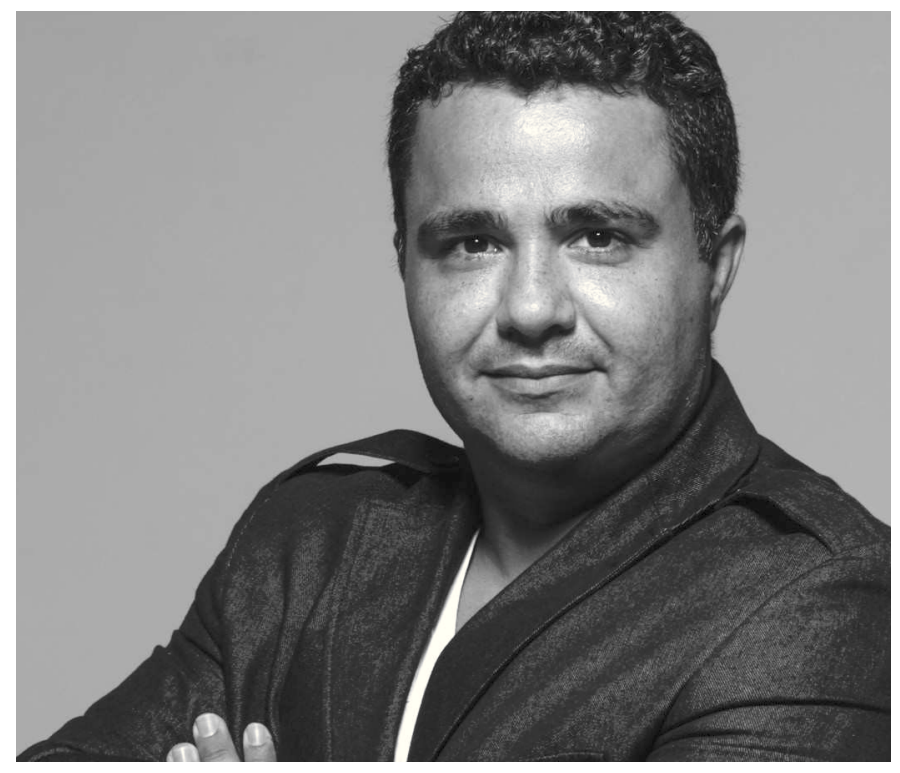

\section{Giorgio Gilwan Silva}

Mestre em Engenharia e Gestão do

Conhecimento/ EGC - Universidade Federal de Santa Catarina.

Professor dos cursos de Design Gráfico,

Produção Publicitária e Fotografia/

Universidade do Vale do Itajaí.

giorgiogilwan@gmail.com 


\section{RESUMO}

A pesquisa aborda os princípios da usabilidade e acessibilidade visando o acesso dos deficientes visuais à programação da televisão digital. A acessibilidade em comunicação é garantida pela legislação brasileira, por meio de decretos e normas. Como metodologia foi utilizada a pesquisa qualitativa e descritiva com baseem fundamentos teóricos, decretos enormas. Os resultados indicam as diretrizes do design e da W3C de acessibilidade que devem ser observadas para o acesso das pessoas com deficiência visual aos meios de comunicação, produtos e serviços.

\section{PALAVRAS CHAVE}

Acessibilidade. TVDigital. Design. Deficientes

\section{ABSTRACT}

The research addresses the principles of usability and accessibility seeking access for the visually impaired to digital television schedule. The communication accessibility is guaranteed by Brazilian law, by means of decrees and regulations. Was used a qualitative and descriptive research based on theoretical fundaments, ordinances and regulations. The results indicate the design guidelines and W3C accessibility that must be observed for the access of people with visual impairments to media, products and services.

\section{KEYWORDS}

Accessibility. Digital. TVDesign. Disabled.

\section{INTRODUÇÃO}

A televisão digital interativa (TVDI) oferece a possibilidade, em relação aos dispositivos analógicos, de um novo suporte de comunicação audiovisual. Destaca-se pela melhor qualidade de áudio e vídeo, com o uso mais eficiente do espectro de frequência. A programação é planejada com o objetivo de conquistar e manter a audiência, por isso busca adaptar seu conteúdo e projeto de comunicação visual aos usuários que deseja atingir. São incluídos neste planejamento os equipamentos que dão acesso à 
interface e a própria interface, com características que ofereçam facilidades de uso às pessoas para que elas se sintam confiantes e satisfeitas em operar com o sistema. Assim, a produção e transmissão dos vídeos, textos, menus e demais elementos visuais de comunicação precisam de vários profissionais, incluindo o designer, para criar a linguagem gráfica; enfatizando o conteúdo da mensagem a ser transmitida e utilizando a interatividade como aliada nesta tarefa. Estes aspectos remetem às técnicas e aos métodos da engenharia de usabilidade e às normas da acessibilidade.

A garantia da acessibilidade em comunicação é relativamente recente na legislação brasileira. No ano de 2005 , foi aprovada a primeira regulamentação neste sentido, por meio do Decreto de Lei no 5.296 . Esta norma estabelece diretrizes gerais a serem observadas para a acessibilidade em comunicação na televisão, onde são consideradas as diversas condições de percepção e cognição, com ou sem a ajuda de sistema assistivo ou outro sistema que complemente necessidades individuais (ABNT-NBR 15290, 2005).

Este decreto estabelece diretrizes para a acessibilidade em comunicação audiovisual dos conteúdos produzidos para que todos possam ter acesso à informação e ao entretenimento proporcionado pela televisão digital interativa (TVDI), incluindo as pessoas com deficiências auditivas, visuais ou cognitivas.

A usabilidade e a acessibilidade estão intrinsecamente focadas nos conceitos fundamentais (diretos humanos - de igualdade, bem estar, saúde), que agregam os valores de interação, praticidade, segurança e funcionalidade para a interface, seu conteúdo e aplicativos de acesso. Diante desta abordagem, esta pesquisa tem como objetivo identificar os critérios a serem adotados na TVDI para apoiar a acessibilidade dos deficientes visuais. Para tanto, abordaram-se os princípios da usabilidade e recomendações do design universal e as diretrizes de acessibilidade os quais poderão ser aplicados ao projeto de interfaces gráficas da TVDI.

Estas diretrizes poderão ser adotadas para o fácil acesso às informações, ao manuseio do controle remoto e, à navegação pelos canais, com audiodescrição das opções do menu e da programação, assim, uma das questões mais relevantes desta pesquisa envolve a acessibilidade e a estrutura da usabilidade destinada a deficientes visuais. 


\section{A ESTRUTURA DA USABILIDADE}

A norma ISO 9241-11 (2002, p. 3) definiu oficialmente o conceito de usabilidade. De acordo com ela, a usabilidade é "a capacidade que um sistema interativo oferece a seu usuário, em um determinado contexto de operação, para a realização de tarefas com eficácia, eficiência e satisfação em um contexto de uso específico". A estrutura da usabilidade segundo a ISO 9241-11 pode ser observada na Figura 1 - Estrutura da UsabilidadeFigura 1. Sua estrutura está diretamente ligada ao diálogo entre o usuário e o sistema em um contexto de uso; sendo intermediada por uma interface, cujo objetivo deve ser obtido com eficácia, eficiência e satisfação, descritas na sequencia.

Figura 1 - Estrutura da Usabilidade

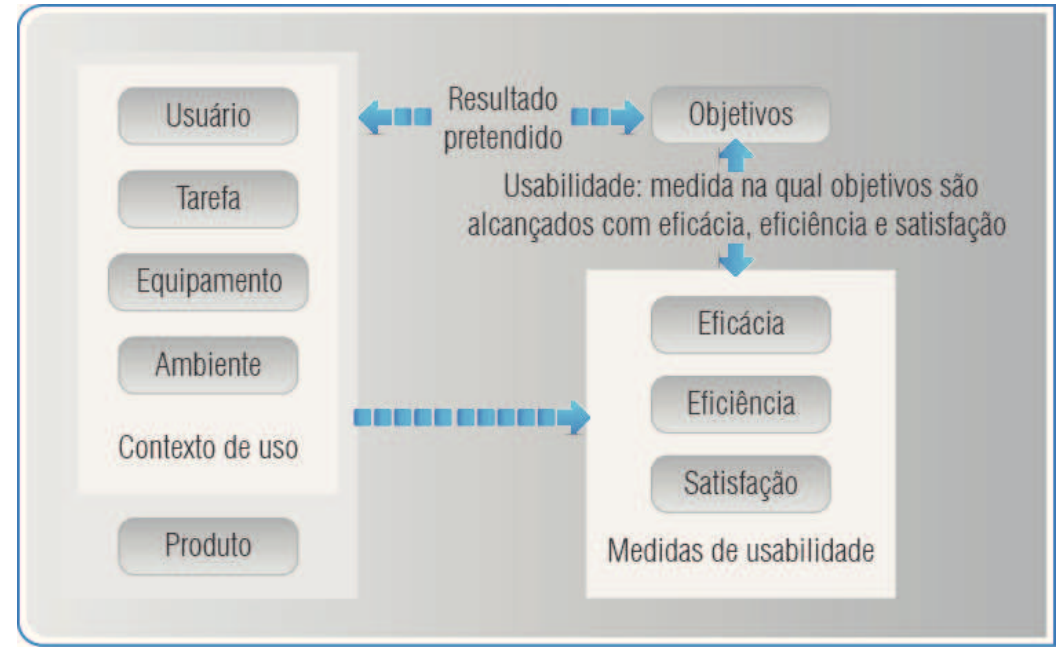

Fonte - Adaptada de ISO 9241-11, 2002.

As recomendações da norma ISO 9241 são de natureza empírica e possuem um perfil prioritariamente sugestivo, ou seja, raramente as recomendações podem ser entendidas como determinações prescritas. São princípios genéricos e, portanto, podem ser aplicados como recomendações gerais, independentemente da técnica específica de diálogo que tenha sido adotada no projeto da interface do produto. No entanto, quando observadas, as recomendações garantem a qualidade dos produtos.

Na norma ISO 9241, a usabilidade e seus compostos, utilizam as seguintes definições:

Eficácia - Permite que o usuário alcance os objetivos iniciais de interação. Pode ser avaliada, quando uma tarefa é finalizada, em termos de qualidade 
do resultado alcançado com o uso do produto.

Eficiência - Refere-se à quantidade de esforço e aos recursos necessários para se chegar a um determinado objetivo. Os desvios que o usuário faz durante a interação e a quantidade de erros cometidos pode servir para avaliar o nível de eficiência da tarefa ou da interação com o produto. Referese à precisão e à completeza com que os usuários atingem seus objetivos, em relação à quantidade de recursos gastos.

Segurança - O aplicativo deve proteger o seu usuário de possíveis erros de entrada e situações indesejáveis, ou seja, proteger o usuário de danos e frustrações em situações potencialmente danosas, aumentando o nível de alerta e prevenindo o erro e se, mesmo assim, ele ocorrer, permitindo a recuperação.

Preece, Rogers e Sharp (2005) acrescentam mais três metas para a usabilidade: Utilidade, Learnability e Memorability:

Utilidade - Mede as funcionalidades que o aplicativo deve realizar, portanto, um aplicativo para consultar dados da conta bancária deve ter todos os dados e ferramentas necessárias para que o usuário complete suas transações bancárias.

Memorability - A palavra em inglês significa "capacidade de memorização". Refere-se à facilidade de lembrar como utilizar os aplicativos, ou seja, não haver necessidade de realizar um novo processo de aprendizagem. Essa meta é importante para aplicativos televisivos, pois usuários que passam muito tempo sem utilizá-lo, atendem a esquecer do passo- a- passo da realização das tarefas desejadas.

Learnability - E tradução livre esta palavra significa "capacidade de aprendizagem". Avalia a facilidade com que o usuário aprende a usar o aplicativo e os dispositivos de entrada de interação. Para que esse aprendizado não se torne um sofrimento para o usuário, é aconselhável o uso de vídeos curtos explicando sua utilização. Quando as pessoas sentem dificuldades no uso da televisão, é comum que troque de canal ou desligue o aparelho.

Os princípios de usabilidade voltam-se à acessibilidade e destinam-se a orientar os designers em relação aos diferentes aspectos de seus projetos. Seus procedimentos não dizem ao designer como projetar interfaces, mas indicam itens que não devem ser esquecidos no momento da concepção dos produtos. Devem, portanto considerar a essência da usabilidade que 
envolve a interface, usuário, tarefa e ambiente, visando uma composição flexível entre os aspectos objetivos que envolvem a produtividade na interação, e os aspectos subjetivos que estão ligados ao prazer do usuário em sua experiência com o sistema.

\section{ACESSIBILIDADE}

A interpretação do termo acessibilidade varia em função de sua contextualização. A Associação Brasileira de Normas Técnicas (ABNT) publicou normas relacionadas à acessibilidade tanto para se referir às condições de alcance, percepção e entendimento, uso seguro e autônomo em edificações, espaço, mobiliário e equipamento urbano, quanto para tratar do acesso das pessoas com deficiências aos meios de comunicação, produtos e serviços.

De acordo com a NBR $15290(2005$, p.2):

A acessibilidade é a possibilidade e condição de alcance para utilização do meio físico, meios de comunicação, produtos e serviços, por pessoa com deficiência. Qualquer entrave ou obstáculo que dificulte ou impossibilite a expressão ou o recebimento de mensagens por intermédio dos meios ou sistemas de comunicação, sendo ou não de massa.

Esta norma apresenta as diretrizes a serem aplicadas para acessibilidade em comunicação na televisão, levando em consideração o grau de deficiência do usuário. Mesmo não mencionando a TVDI, suas diretrizes podem ser aplicadas a sua programação, observando os dispositivos da norma técnica (ABNT NBR 15290), que estabelecem critérios básicos para a promoção da acessibilidade para a busca de soluções que atendam aos direitos dos deficientes visuais à informação.

\subsection{DIRETRIZES DE ACESSIBILIDADE}

A ABNT NBR 15290, apresenta diretrizes para a Acessibilidade em Comunicação na Televisão em âmbito geral, não sendo abordado 
especificando recursos tecnológicos da TVDI. No quadro 1 apresenta-se os componentes da TVDI e as especificações das diretrizes previstas para a acessibilidade da comunicação.

Quadro 1 - Diretrizes de Acessibilidade para a TV.

\begin{tabular}{|c|c|}
\hline \multicolumn{2}{|c|}{ DIRETRIZES PARA GARANTIR A ACESSIBILIDADE } \\
\hline Componentes & Diretrizes \\
\hline $\begin{array}{l}\text { Sistemas CC } \\
\text { (legenda) e SAP } \\
\text { (áudio) }\end{array}$ & $\begin{array}{l}\text { Televisores - devem dispor de decodificador interno de CC e } \\
\text { de SAP. } \\
\text { Sistema - adotar caracteres na cor branca, por permitir } \\
\text { maior eficácia na leitura. A tipologia deve dispor de todos os } \\
\text { caracteres da língua portuguesa. A fonte deve ser integrada } \\
\text { ao decodificador. Cada linha deve apresentar no máximo } 32 \\
\text { caracteres, centralizados em relação à tarja. }\end{array}$ \\
\hline $\begin{array}{l}\text { Dispositivo } \\
\text { Decodificador }\end{array}$ & $\begin{array}{l}\text { Devem ser disponíveis todos os caracteres mencionados } \\
\text { acima, em fonte. Requisitos da ABNT NBR } 9050\end{array}$ \\
\hline Tipologia e Fontes & $\begin{array}{l}\text { a) largura = 2/3 da altura; } \\
\text { b) espessura do traço = 1/7 da altura (caractere claro sobre } \\
\text { fundo escuro); } \\
\text { c) distância entre letras = 1/5 da altura; } \\
\text { d) distância entre palavras = } 2 / 3 \text { da altura; } \\
\text { e) intervalo entre linhas = 1/5 da altura1); } \\
\text { f) altura da letra minúscula = 2/3 da altura da letra maiúscula. }\end{array}$ \\
\hline $\begin{array}{l}\text { Identificação } \\
\text { dos Recursos } \\
\text { Disponíveis e das } \\
\text { Características da } \\
\text { Programação deve } \\
\text { Constar nas Grades } \\
\text { de Programação, } \\
\text { Divulgadas de Forma } \\
\text { Sonora, Impressa e } \\
\text { Digital. }\end{array}$ & $\begin{array}{l}\text { a) CC - legenda oculta; } \\
\text { b) DUB - dublado; } \\
\text { c) LSB - janela de LIBRAS; } \\
\text { d) DIS - áudio com a descrição de imagens e sons; } \\
\text { e) ORG - som original. }\end{array}$ \\
\hline Identificação Visual & Informadas o início de cada bloco do programa. \\
\hline
\end{tabular}




\begin{tabular}{|c|c|}
\hline $\begin{array}{l}\text { Linha } 21 \text { e } 284 \text { - } \\
\text { Linhas de Sinal de } \\
\text { Vídeo }\end{array}$ & Devem ser utilizadas para transmissão de CC. \\
\hline $\begin{array}{l}\text { Programa Secundário } \\
\text { de Áudio (SAP) }\end{array}$ & $\begin{array}{l}\text { Deve ser usado para transmissão: } \\
\text { a) do som no qual o programa foi originalmente produzido, } \\
\text { sempre que o mesmo for transmitido de forma dublada, pelo } \\
\text { canal principal de áudio; } \\
\text { b) do áudio com a descrição de imagens e sons, quando o } \\
\text { programa produzido for originalmente em português; } \\
\text { c) da dublagem, sempre que o programa transmitido for em } \\
\text { língua estrangeira. }\end{array}$ \\
\hline Retransmissoras & $\begin{array}{l}\text { Devem garantir que a legenda oculta e o conteúdo sonoro } \\
\text { transmitido através do SAP sejam retransmitidos em } \\
\text { conformidade com o sinal emitido pela matriz, ou cabeça de } \\
\text { rede. }\end{array}$ \\
\hline $\begin{array}{l}\text { Tabela de caracteres } \\
\text { para produção e } \\
\text { reprodução }\end{array}$ & $\begin{array}{l}\text { A tabela de caracteres de legenda das linhas } 21 \text { e } 284 \text { (linhas } \\
\text { de sinal de vídeo), determinada pelo padrão do equipamento, } \\
\text { devem atender, as mesmas diretrizes adotadas para o sistema. }\end{array}$ \\
\hline $\begin{array}{l}\text { Diferenciação - Áudio } \\
\text { com a Descrição de } \\
\text { Imagens e Sons }\end{array}$ & $\begin{array}{l}\text { A descrição de imagens e sons deve atender aos requisitos: } \\
\text { Transmitir de forma sucinta o que não pode ser entendido } \\
\text { sem a visão. Devem ser evitados monotonia e exageros. } \\
\text { A descrição deve estar diferenciada do som do programa. } \\
\text { Para permitir melhor compreensão do programa, sempre que } \\
\text { possível, aproveitar as pausas naturais entre os diálogos. }\end{array}$ \\
\hline $\begin{array}{l}\text { Compatibilidade com } \\
\text { o Programa }\end{array}$ & $\begin{array}{l}\text { a) a narração deve ser objetiva na programação para adultos e } \\
\text { mais poética em programas infantis; } \\
\text { b) em filmes de época devem ser fornecidas informações que } \\
\text { facilitem a compreensão do programa; } \\
\text { c) a descrição subjetiva deve ser evitada. }\end{array}$ \\
\hline
\end{tabular}

Fonte - Adaptada da ABNT NBR 15290 (2005).

As diretrizes acima apresentadas foram elaboradas com base nos preceitos do design universal, critérios de usabilidade, design de interfaces e recomendações da acessibilidade para Web. As normas visam atender 
as diversas condições de percepção e cognição que complementam as necessidades individuais. Na verdade para ser considerada acessível, a programação da TVDI também deve atender as recomendações desta norma. Isto é possível, porque a televisão digital dispõe de qualidade de sinal de áudio e vídeo, com imagem limpa, sem interferências de ruídos e dos "chuviscos".

A acessibilidade é importante para garantir o direito do cidadão, e iniciativas têm sido tomadas por órgãos internacionais no sentido de promovê-la na web. O World Wide Web Consortium W3C, por exemplo, é um desses órgãos que auxiliam os desenvolvedores a criar sites que alcancem seu potencial máximo de acessibilidade. Os deficientes visuais utilizam os recursos da internet com facilidade, para eles, foi uma porta que se abriu para o mundo das comunicações e do conhecimento. Como se trata de uma mídia digital, algumas diretrizes disponibilizadas por estes órgãos podem ser aplicadas na TVDI, por exemplo, os princípios da percepção, da operacionalização e da compreensão. Visando esta possibilidade apresentam-se as diretrizes WCAG para a acessibilidade na Web.

\subsection{DIRETRIZES WCAG PARA A ACESSIBILIDADE}

Em meados de 1997, foi criado pelo Word Wide Web Consortium (W3C) o grupo de pesquisa e desenvolvimento Web Accessibility Iniative (WAl), tendo como direcionamento criar e manter diretrizes e materiais para programar e divulgar ao mundo uma web acessível. O WAl é patrocinado pelo Departamento de Educação dos Estados Unidos, por comissões europeias e por várias empresas (IBM, Microsoft Corporation, SAP) e outras organizações envolvidas que colaboram para o fortalecimento desta iniciativa (KAMINSKI, 2008).

Com seus objetivos de criar, manter e divulgar diretrizes para que os desenvolvedores incluam no código fonte das páginas web recomendações da acessibilidade. Diante disto, cabe aos designers utilizarem estas delimitações para criação das interfaces gráficas visuais acessíveis. As recomendações propostas pelo WAl são apresentadas no documento WCAG (Web Content Acessibility Guidelines).

O objetivo da contextualização destas diretrizes listadas da Web Content Acessibility Guidelines no presente estudo consiste em direcioná-las para 
outra mídia digital, ou seja, consiste na tentativa de adaptar tais diretrizes para a realidade da TVDI. O Quadro 2 mostra às diretrizes propostas pela WAl, a esquerda estão os princípios, a direita estão dispostas as diretrizes relacionadas a cada princípio do qual fazem parte. As diretrizes se subdividem em tópicos, classificados de acordo com o seu nível de conformidade (WCAG, 2008).

Quadro 2 - Princípios e Diretrizes Propostas da WAI

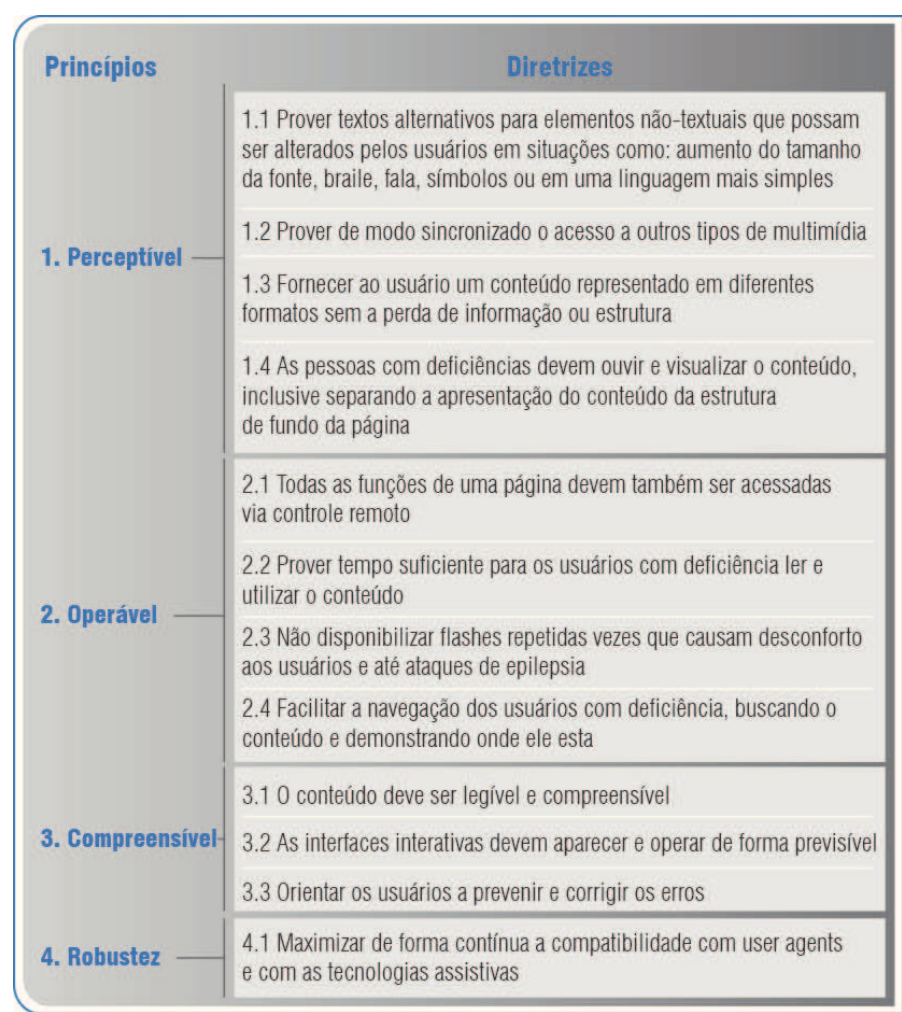

Fonte: W3C (2008).

Como pode ser constatado, cada princípio é subdividido em outros tópicos facilitando a compreensão com vistas a sua validação. Cada tópico deve ser atendido para atingir o sucesso do princípio, de acordo com a necessidade o usuário. A seguir, descrevem-se os princípios e diretrizes propostas da WAI (W3C, 2008).

Princípio 1: Perceptível - A informação e os componentes da interface devem ser apresentados aos usuários em formas que eles possam perceber. 
Recomendação 1.1 - Alternativa de Texto: prover texto para qualquer conteúdo não textual permitindo, assim, que o mesmo possa ser alterado para outras formas mais adequadas à necessidade do indivíduo, tais como impressão em caracteres ampliados, braile, fala, símbolos ou linguagem mais simples.

Recomendação 1.2 - Mídias com Base no Tempo: fornecer alternativas para acesso a outros tipos de mídias. Neste caso, apenas áudio e apenas vídeo podem ser pré-gravados. Esta recomendação é muito importante para os deficientes visuais, pois é fornecida uma alternativa para mídia baseada no tempo, com audiodescrição das informações do conteúdo composto por apenas áudio pré-gravado. Podem ser fornecidas legendas para a totalidade do áudio pré-gravado em uma mídia sincronizada, ou também em linguagem de sinais.

Recomendação 1.3 - Adaptável: Criar conteúdos que possam ser apresentados de diferentes maneiras (um layout mais simples) sem a perda de informação ou estrutura. O conteúdo pode ser apresentado em uma sequência que não afeta seu significado. Podem ser observadas as características sensoriais do usuário, fornecendo para compreensão e utilização dos conteúdos, componentes; tais como forma, tamanho, localização visual, orientação ou som.

Recomendação 1.4 - Discernível: Facilitar a audição e a visualização de conteúdos aos usuários, incluindo a separação do primeiro plano e do plano de fundo. Para esta recomendação pode ser utilizada a cor como um elemento visual, além de mecanismo de controle do áudio; bem como imagens de textos ampliados com alto contraste, de modo aumente a visualização das informações. Textos e imagens ampliados com uma relação de contraste.

Princípio 2: Operável - Os componente de interface de usuários e a navegação devem ser operáveis.

Recomendação 2.1 - Teclado: Toda a funcionalidade do conteúdo deve ser operável por meio de uma interface de teclado sem a necessidade de qualquer espaço de tempo entre cada digitação individual, exceto quando a função subjacente requeira a entrada de dados que dependa da cadeia de movimento do usuário e não apenas dos pontos finais.

Recomendação 2.2 - Tempo: Fornecer tempo suficiente aos usuários 
para lerem e utilizarem conteúdo, para ligar, desligar, ajustar ou prolongar. O usuário é avisado antes do tempo expirar, tendo alguns segundos para realizar a ação.

Recomendação 2.3 - Não fornecer flashes repetidas vezes, os quais causam desconforto aos usuários.

Recomendação 2.4 - Navegável: Fornecer formas de ajudar os usuários a navegar, localizar conteúdos e determinar o local onde estão na navegação. Disponibilizar um mecanismo para descrever as páginas ou as finalidades às quais se destinam. A sequência da navegação pode ser apresentada de forma que o significado e a operabilidade sejam preservados.

Princípio 3: Compreensível - A informação e a operação da interface de usuário devem ser compreensíveis.

Recomendação 3.1 - Legível: Tornar o conteúdo de texto legível e compreensível.

Recomendação 3. - Previsível: Fazer com que as páginas web surjam e funcionem de forma previsível.

Recomendação 3.3 - Assistência de Entrada: Ajudar os usuários a evitar e corrigir erros. $\mathrm{O}$ erro deve ser detectado automaticamente e descrito ao usuário, dando oportunidade de correção.

Princípio 4: Robusto - O conteúdo tem de ser robusto o suficiente para poder ser interpretado de forma concisa por diversos agentes do usuário, incluindo tecnologias assistivas.

Recomendação 3.1 - Compatível: Significa maximizar a compatibilidade com os atuais e futuros agentes de usuário, incluindo tecnologias assistivas. Todos os componentes de interface de usuários como nome e função, podem ser determinados de forma programática e as notificações sobre alterações destes itens devem ser disponibilizadas por tecnologias assistivas.

Em síntese, os tópicos de cada princípio trazem uma variedade de orientações que corroboram com a eficácia de cada diretriz. O primeiro princípio, acima descrito, está relacionado com a percepção, como mostra à diretriz (1.1) que aborda a utilização de textos, no guia da WAI de aplicabilidade para TVD, mostra algumas delimitações no layout interativo, no uso tipográfico, assim como, tipo de fonte e tamanho. Com isto neste princípio 
que aborda a inserção de textos alternativos para os variados conteúdos não textuais; tais como: figuras, vídeos, animações, botões gráficos, componentes de programação; devem ser enquadradas as delimitações do guia do WAI apresentado no documento WCAG (Web Content Acessibility Guidelines).

Nesse sentido, a disponibilidade de textos alternativos deve permear a sincronização de mídias com base no tempo, diretriz (1.2) com a mídia visual, pois, se a sincronia de texto e imagem não estiver adequada, esta opção estará obsoleta. Na terceira diretriz deste mesmo princípio (1.3) ser adaptável, pode-se direcionar para a TVD a apresentação do conteúdo de diferentes formatos, almejando que não haja perda de informações ou perdas sobre a estrutura do layout da interface interativa. Por fim, a quarta diretriz (1.4) ser discernível, pode ser utilizada para a otimização da interface digital, devido o layout da informação principal.

Como as pessoas com deficiência visual não podem ver, ou possuem baixa visão, torna-se necessário descrever a principal informação do texto. Em acréscimo as informações sonoras devem conter algum dispositivo que possibilite a pausa para o melhor entendimento da informação.

O princípio dois trata da operabilidade. A priori o teclado (2.1) pode ser usado na operacionalização das funções da interatividade da TVD. A implementação e inclusão das tecnologias de uso do sistema digital de televisão estão em amplo desenvolvimento, mas em fase de implementação, diante disto, recomenda-se nesta diretriz inicial a possibilidade de utilizar teclado, controle remoto ou tela virtual e que sejam operáveis para a interface interativa no set-top-box, aparelho que conectado à TV permite o recebimento do sinal digital no aparelho de TV analógico convencional. $\mathrm{O}$ direcionamento deste aparelho permeia a atenção das pessoas com baixa visão ou pessoas cegas, as quais que por ventura tenham dificuldade em utilizar os dispositivos que necessitam a coordenação olho-mão.

$\mathrm{Na}$ abordagem do terceiro princípio - compreensibilidade evidencia-se a utilização de conteúdo, funcionalidade e transmissão na interação da TVD de modo a possibilitar sobremaneira o entendimento. Todavia, é necessário indicar o idioma padrão da interface interativa e das sessões nele contidas (3.1). A previsibilidade (3.2) da interface deve ser colocada em foco, pois, o usuário não deverá ter sua atenção desviada do contexto da interação. Diante disto, não se utiliza outras janelas na interface de interação que possam criar ruídos na compreensão do conteúdo inicial (3.2). 
Já a terceira diretriz (3.3) deste princípio, refere-se à possibilidade de ocorrência de erros pelo sistema interativo, momento em que o usuário deverá ser informado sobre o ocorrido, de maneira que evite erros. Para tal, podem ser incluídas indicações que facilitem o entendimento do conteúdo de interatividade da TVDI.

Por fim, o quarto e último princípio, aborda a necessidade de compatibilidade e robustez do sistema interativo para TVDI com o navegador, media player e tecnologias assistivas. Neste contexto, a visualização do conteúdo no Sistema Brasileiro de TV Digital (SBTVD), realiza-se em um receptor de sinal digital, o set-top-box digital ou URD, que executará o middleware GINGA. De acordo com o Site oficial do middleware (camada de software que gerencia a interatividade), o Ginga é constituído por um conjunto de tecnologias padronizadas e inovações brasileiras que tornam a especificação de middleware a mais avançada do mercado permitindo que a interatividade no SBTVD seja acessada com ou sem canal de retorno, pois dependendo do nível de interatividade que a emissora ou produtora deseja que o telespectador tenha acesso, será evidenciada essa necessidade. É interessante ressaltar que o acesso à interatividade não depende exclusivamente do canal de retorno, mas da criatividade dos conteúdos e aplicativos utilizados pelas emissoras.

Diante destas possibilidades das diretrizes de acessibilidade, os designers podem sugerir ou projetar equipamentos; controle remoto, por exemplo; de acesso à programação com funções adequadas a deficientes, tais como deficientes visuais.

\section{DEFICIÊNCIAS VISUAIS}

Problemas físicos diversos podem levar a deficiências, como problemas visuais, auditivos, motores, cognitivos, da fala e do sistema nervoso. Com o surgimento das tecnologias digitais, a inclusão digital social dessas pessoas tem favorecido a inclusão social, o que faz com que o desenvolvimento na área da acessibilidade possa ser utilizado, também pela TVDI.

Este trabalho considerou a acessibilidade tendo como foco os deficientes visuais. Para tal considerou-se a definição legal de deficiência visual, dada pelo decreto $n^{\circ} 3298$ de 20 de dezembro de 1999, Art. 4 - inciso III, que dispõe: 
Deficiência visual: cegueira, na qual a acuidade visual é igual ou menor que 0,05 no melhor olho, com a melhor correção óptica; baixa visão, que significa acuidade visual entre 0,3 e 0,5 no melhor olho, com a melhor correção óptica; os casos nos quais a somatória da medida do campo visual em ambos os olhos for igual ou menor que 60\%; ou a ocorrência simultânea de quaisquer condições anteriores.

De acordo com a Organização Mundial da Saúde, OMS, no Brasil, a prevalência de cegueira na população é de $0,3 \%$ (zero vírgula três) por cento e de baixa visão, 1,7\% (um vírgula sete) por cento. A pessoa com baixa visão é aquela que mesmo após tratamentos ou correção óptica apresenta diminuição considerável de sua função visual. A maior parte da população considerada cega, realmente tem baixa visão e é, a princípio, capaz de utilizar sua visão para realizar tarefas. Para cada pessoa cega há em média, 3 (três) ou 4 (quatro) com baixa visão. $O$ paciente verdadeiramente com cegueira é aquele que perde totalmente a visão por causas que vão desde traumas oculares até doenças congênitas.

A prevalência de doenças oculares que levam ao comprometimento da visão cresce com o avanço da idade. As taxas maiores de cegueira e baixa visão são observadas com o aumento da vida média da população. Na população com mais de cinquenta anos de idade as principais causas de cegueira são: catarata, o glaucoma, a retinopatia diabética e a degeneração macular (perda da visão no centro do campo visual, a mácula) relacionada à idade (OMS, 2011).

Os autores Ochaita e Rosa (2005), explicam que embora as pessoas cegas tenham comprometimento na aquisição das informações visuais, são capazes de compreenderem os fatos que estão acontecendo no ambiente em que ele se encontra, por meio de ferramentas alternativas. A invenção do braile propiciou a inclusão do deficiente visual nos processos de escrita e de leitura, mostrando a possibilidades de integração dessas pessoas por meio da leitura.

Acredita-se que a leitura, a escrita e a internet são os principais recursos para os deficientes visuais obter informações e conhecimentos. A televisão também poderá em breve disponibilizar serviços interativos educacionais, comerciais e de entretenimento para lares, salas de aula, locais de trabalho e a acessibilidade atingirá um número maior de pessoas, principalmente as 
com deficiência visual.

Para a acessibilidade, existem também, equipamentos para cálculos matemáticos, lentes de aumento e acesso a internet com o software virtual vision, que permite ao deficiente visual a leitura da tela transformada em fala, entre outros. Mas, para que os deficientes visuais possam beneficiar-se destes dispositivos, as imagens e as cenas precisam ser transformadas em palavras, com o recurso da tradução, como a audiodescrição, a qual será apresentada a seguir.

\subsection{RECURSO DE ACESSIBILIDADE - AUDIODESCRIÇÃO}

A audiodescrição é, sem dúvida, o recurso que pode tornar a televisão brasileira acessível, não apenas para pessoas com deficiência visual ou intelectual, mas também para idosos, disléxicos e para todos aqueles com dificuldades de compreensão de audiovisuais e leitura de textos em imagens. A audiodescrição consiste na transformação de imagens em palavras para que informações-chave transmitidas visualmente não passem despercebidas e também possam ser acessadas por pessoas cegas ou com baixa visão.

Segundo Romeu Filho (2010), todos os aparelhos de televisão digital disponíveis no mercado têm capacidade para até quatro canais de áudio, dois deles de alta qualidade, sendo que a audiodescrição será transmitida por um dos canais de baixa resolução.

É este recurso que transfere a dimensão visual de um espetáculo para o verbal, por meio de informação sonora, ampliando, desta forma, o entendimento e promovendo o acesso à informação e à cultura. Ele possibilita que pessoas com deficiência visual assistam a peças, filmes, programas de televisão, exposições, espetáculos de ópera, etc., em igualdade de condições às pessoas que enxergam sem deficiência, o que atende ao conceito de acessibilidade.

A política de promoção da audiodescrição é prevista para a televisão digital brasileira, visando à inclusão social de pessoas com deficiência visual através da inserção deste recurso na programação televisiva aberta. Para isso, foram elaboradas normas que orientam sua implementação.

A norma (NBR15290, 2005) da Associação Brasileira de Normas Técnicas (ABNT) de Acessibilidade em Comunicação na Televisão, definiu os padrões de formatação e exibição de recursos como legendas ocultas, SAP (programa de áudio secundário), janela de exibição de LIBRAS (sistema linguístico de 
comunidades surdas do Brasil) e cores de fundo, além de padrões para diversos outros elementos.

É importante salientar que as primeiras normas, assim como a NBR 15290 da ABNT (2005), foram elaboradas tendo como base os recursos de acessibilidade existentes no padrão de televisão analógico, visto que, até o momento da publicação dessas normas, ainda não havia definição sobre o sistema de televisão digital a ser adotado no Brasil. De modo a atender as especificações da televisão digital, o governo federal instituiu norma complementar, conforme Portaria n० 310.

A Portaria no 310, de 27 de junho de 2006, aprovou a Norma Complementar $n^{\circ}$ 01/2006 - Recursos de Acessibilidade, para pessoas com deficiência, na programação veiculada, nos serviços de radiodifusão de sons e imagens e de retransmissão de televisão, passou a vigorar com as alterações da Portaria no- 188, de 24 de Março de 2010, do Ministro de Estado das Comunicações, incluindo no subitem 3.3 o recurso de acessibilidade audiodescrição.

3.3. audiodescrição: é a narração, em língua portuguesa, integrada ao som original da obra audiovisual, contendo descrições de sons e elementos visuais e quaisquer informações adicionais que sejam relevantes para possibilitar a melhor compreensão desta por pessoas com deficiência visual e intelectual.

Diante do exposto, a audiodescrição é considerada recurso de acessibilidade à informação, à comunicação, à educação e à cultura e que pode ser usada na programação da TVDI, conforme recomendações das diretrizes de acessibilidade, do guia do WAl e das normas governamentais. Uma faixa de áudio adicional à transmissão regular de televisão descreve verbalmente detalhes visuais importantes de cenários, figurinos, expressões faciais e corporais, ações, entrada e saída de personagens e todos os elementos relevantes para a compreensão e fruição do conteúdo visual e/ou sonoro. Com estes recursos os espectadores invisuais ou deficientes visuais graves, podem acompanhar melhor e com mais detalhe o desenrolar do programa transmitido. 


\section{CONSIDERAÇÕES FINAIS}

A essência da usabilidade é a interação entre sistema, usuário, tarefa e ambiente. A interface com o produto favorece a acessibilidade, quando atende a norma ISO 9241-11, que define usabilidade como a capacidade que um sistema interativo oferece a seu usuário, em determinado contexto de operação.

O presente trabalho pretendeu abordar os conhecimentos específicos em acessibilidade, na busca das diretrizes, que favoreçam a acessibilidade das pessoas com deficiências, em especial aos deficientes visuais.

Todas as diretrizes abordadas indicam o uso equitativo das informações e conhecimentos, portanto devem ser disponíveis para todos, atendendo a privacidade, a segurança e a proteção dos usuários. A informação e os componentes da interface têm de ser apresentados aos usuários, de modo que possam perceber e entender o conteúdo. Todas as diretrizes tem a mesma pretensão, ou seja, o atendimento a todos os usuários, o que inclui as pessoas com algum tipo de deficiência, mais especificamente os deficientes visuais. Devem proporcionar à flexibilidade no uso do produto com diferentes opções de utilização, permitindo acesso a todos.

A informação tem que ser perceptível, chegando ao usuário de forma eficaz, independentemente do ambiente ou das suas capacidades sensoriais. Em relação aos componentes da interface com os usuários e com a navegação no sistema, estes devem ser fáceis de utilizar e compreender, de acordo com a capacidade e conhecimento de cada pessoa. Por isso, tem que ser coerente com as expectativas e intuição do usuário.

Recomenda-se as diretrizes abordadas acima, como soluções para o desenvolvimento e qualidade da interface com os produtos, sistema e ambientes, de forma que todas as pessoas sejam beneficiadas e se promova assim, a acessibilidades. Sendo aplicadas as recomendações das diretrizes, as pessoas com necessidades especiais, podem perceber, compreender, navegar e interagir com os sistemas. Inclui possibilidade de acesso para pessoas com deficiências visuais, auditivas, físicas, na fala, na cognição, e neurológicas.

O decreto governamental que trata do acesso à informação e comunicação estabelece prazo (previsto para 2018) para implantação de estruturas das informações, dos sistemas de navegação, com recomendações de acessibilidade. $O$ que se espera é que na prática usual, sejam adequadas 
as pessoas com deficiência visual. Aplicada a TVDI, implica na habilidade das emissoras de projetar equipamentos e dispositivos de modo compreensível e eficiente a estes telespectadores. Portanto, acessibilidade significa acesso para todas as pessoas, perceber, compreender, navegar e interagir com os sistemas e os produtos.

\section{REFERÊNCIAS}

ABNT NBR 15290, Acessibilidade em Comunicação na Televisão. Associação Brasileira de Normas Técnicas, 15290 - 30/11/2005, Rio de Janeiro.

ISO-9241. Ergonomic requirements for office work with visual displayterminals, Part 11 Usability Statements; Draft International Standard, 1998.

KAMINSKI, Douglas. Sistema Hipermídia Adaptativo Acessível. Dissertação de Mestrado. 93p. Universidade Federal de Santa Catariana, Programa De PósGraduação em Engenharia e Gestão do Conhecimento, 2008.

Ministério das Comunicações. Brasília. Portaria no 188 C2011, disponível em: <http://www.mc.gov.br/images/o-inisterio/legislacao/portarias/portaria-pdf >. Acesso em 05 julho de 2011.

OCHAITA, E. e ROSA, A. Percepção, ação e conhecimento nas crianças cegas. In: COOL, C. PALACIOS, J. MARCHESI, A. (Orgs.). Desenvolvimento psicológico e educação: necessidades educativas especiais e aprendizagem escolar. Porto Alegre: Artes Médicas, 1995.

PREECE, J; ROGERS, Y; SHARP, H. Design de Interação: Além da interação homem computador. Porto Alegre: Bookman, 2005.

ROMEU FILHO, Paulo. Políticas Públicas de Acessibilidade para Pessoa com Deficiência - Audiodescrição na Televisão Brasileira. IN: Audiodescrição: Lívia Maria Villela de Mello Motta, Paulo Romeu Filho (orgs). Transformando imagens em palavras São Paulo: Secretaria dos Direitos da Pessoa com Deficiência do Estado de São Paulo, 2010.

\section{SITES}

DECRETO No 3.298, de 20 DE Dezembro de 1999, C1999. Política Nacional para a Integração da Pessoa Portadora de Deficiência. Disponível em

http://www.mpes.gov.br/anexos/centros_apoio/arquivos/_DECRETO

Acesso em 14 de janeiro de 2011.

PORTARIA No- 188, de 24 de Março de 2010,. Ministro de Estado das Comunicações, C2010. Disponível em http:// /blogdaaudiodescricao.blogspot. com/2010/03/portaria-mc-n-1882010.html> - Acesso em 20/01/2011.

WEB ACCESSIBILITY INITIATIVE, C2010. Disponível em: <http://www.w3.org/ WAI/>. 2008. Acesso em 4 dezembro de 2010.

WCAG: Web Content Accessibility Guidelines2.0, C2011. Disponível em:<http:// 
www.w3.org/TR/WCAG20/>. Acesso em 03 janeiro de 2011.

MIDDLEWARE GINGA. http://www.ginga.org.br (2008), C2008. Disponível em: www.broadbandbananas.com. Acesso em 20 de julho de 2011.

Dra. Icléia Silveira é doutora em Design pela Pontifica Universidade Católica do Rio de Janeiro PUC/RIO. Mestre em Engenharia de Produção pela Universidade Federal de Santa Catarina UFSC. Especialista em Moda pela Universidade do Estado de Santa Catarina UDESC. Especialista em Atuação para Docente em Nível Superior pela Universidade Federal de Santa Catarina - UFSC. Licenciada em Geografia pela Universidade Federal de Santa Catarina - UFSC. Professora Efetiva do Departamento de Moda da Universidade do Estado de Santa Catarina UDESC. Coordenadora do LaCRIAT - Laboratório de Tecnologia e Economia Criativa. Área de atuação - Tecnologia do Vestuário, Ergonomia, Modelagem Plana e Moulage do Vestuário e Processos Produtivos; Gestão do Conhecimento em Negócios de Moda e Aprendizagem Organizacional.

Giorgio Gilwan da Silva atua como Coordenador dos Cursos Tecnológicos de Design Gráfico e Fotografia e do Bacharelado em Design com linha de formação em Design de Jogos e Entretenimento Digital na UNIVALI - Universidade do Vale do Itajaí no Campus Florianópolis. Possui graduação em Design Gráfico UDESC (2005), Especialização em Design Gráfico e Estratégia Corporativa UNIVALI (2006) e Mestre pelo Programa de Pós-Graduação em Engenharia e Gestão do Conhecimento da

Recebido em: 10/09/2014; Aceito em: 27/11/2014.

Esta obra foi licenciada com uma Licença Creative Commons. Universidade Federal de Santa Catarina EGC/UFSC no Projeto Formação de Recursos Humanos para TV Digital com Foco em Conteúdo e Serviços (2011). Tem experiência de mercado e de ensino nas áreas de Design Gráfico. Professor da UNIVALI, cursos de Design Gráfico, Produção Publicitária e Fotografia. Coordenador do Laboratório de Criação Digital. 